\title{
Social and psychological aspects of environment-based health risk assessment
}

\author{
M. V. Kiseleva ${ }^{1}$, A. V. Kiselev ${ }^{2}$
}

${ }^{1}$ St. Petersburg State Institute of Psychology and Social Work, 13A, 12-ya liniia V. O., St. Petersburg, 199178, Russian Federation

${ }^{2}$ North-Western State Medical University named after I. I. Mechnikov, 41, Kirochnaya ul., St. Petersburg, 191015, Russian Federation

For citation: Kiseleva M.V., Kiselev A.V. Social and psychological aspects of environment-based health risk assessment. Vestnik of Saint Petersburg University. Medicine, 2020, vol. 15, issue 2, pp. 142152. https://doi.org/10.21638/spbu11.2020.206

The authors are mainly focused on special features of using art-therapeutic techniques to facilitate adaptation of several categories of the population to the information about environment-based health risks. They consider the methodological issues of presenting the ideas about health risks within the medical ecological content, of informing about those risks, since the lack of attention to those issues leads to additional anxiety in the population, as well as methods of correction of the latter through art-therapy methods developed by the authors. A psychological support program is suggested, which consists of three stages: diagnostic, psychological correction, psychological and social support. The first stage suggests psychological diagnostics, which include methods that allow for psychological and emotional background assessment. Based on the results of the diagnostics and social data, a complex assessment is made about the main problems of a person and a decision is made about the participation in psychological correction, which consists of individual and groups sessions. The second stage is aimed at the correction of negative emotions and feelings, as well as reaching solutions that are more complex. Art-therapy is suggested as the main psychosocial correction method, the use of which can create safe art-therapeutic environment, where the main means of interaction is a constructive dialogue, based on creating and examining an art product of a client, 'clientart product-psychologist', where the client feels protected enough to express their feelings. At the third stage, the clients continue to work with the psychologist as part of the psychological social support, the essence of which is given in this article as well.

Keywords: quality of human life, health risk, population environment, art-therapy methods, anxiety, visual arts therapy, play therapy.

\section{Introduction}

Modern society is characterized by intensive development and use of different technological solutions, aimed at the improvement of modern quality of life. However, this social path is also connected with denaturation of the environment that leads to different medical ecological problems burdened by psychological issues.

Quality of life is a multifaceted notion, which is defined by numerous objective and subjective circumstances that are part of every member of our society. As a rule, quality of life is understood as an interdisciplinary notion, as an efficiency characteristic of all facets of human life, the level of material, spiritual, and social needs satisfaction, the level

(c) Санкт-Петербургский государственный университет, 2020 
of intellectual, cultural, and physical development, as well as the safety of life [1]. According to the definition by World Health Organization (WHO) this notion includes physical, psychological, emotional and social health of a human being, based on their perception of their role in the society [2].

On the threshold of the Ecology Year in Russia (2017), the president of the Russian Federation, V. V.Putin, ratified a list of assignments, one of which was the assignment for the Government of the Russian Federation together with interested government authorities of the subjects of the Russian Federation to prepare and present suggestions on the environmental norms, based on health risks assessment according to the sanitary rules and regulations. In the following years, a number of legislative solutions were developed and presented, and they found their way into the appendix and changes of the legislative field of the Russian Federation that refer to this assignment.

By the decree of the president of the Russian Federation, as of May $7^{\text {th }}, 2018$ no. 204 "On national goals and priority tasks of the Russian Federation development up to year 2024" there were set 9 national goals of government development. In order to fulfil those national goals of the Russian Federation development, main areas of activity of the Russian Federation Government were established up to year 2024, which in their turn defined the system of priorities and goal pinpoints in the midterm period.

Health risk assessment as part of the ecological task-solving has been implemented in the Russian Federation for over 20 years since the decree of the Chief Sanitary Physician of the Russian Federation and the Chief State Conservation Inspector of the Russian Federation "On using risk assessment methods to control the quality of environment and health of the population in the Russian Federation" as of November 10, 1997 no. 25 and 03-19\24-3486 [3]. And the main document that implements these methods is the official Manual on health risk assessment of the population under the exposure of chemical substances that pollute environment (Manual P2.1.10.1920-04) [4]. A number of methodological recommendations were also developed on health risk assessment not only for chemical pollution, but also for the factors of a different nature.

A number of factors of environmental conditions that influence the health of the population in different subjects of the Russian Federation includes groups of social and economy, sanitary and hygienic factors, as well as factors that constitute the way of life of the population [5].

According to the Federal law as of March $30^{\text {th }}, 1999$ no. 52-FZ "On sanitary and epidemiological welfare of the population, environmental factors are biological (viral, bacterial, parasitic and other), chemical, physical (noise, vibration, ultrasound, heat, ionizing, non-ionizing and other emissions), social (nutrition, water supply, everyday life, labor and rest) and other factors of the environmental conditions that influence or do not influence human beings and (or) the health of the future generations. Influence levels assessment of different environmental factors on the health of the population is conducted as part of social hygienic monitoring in the subjects of the Russian Federation.

In 2018, the most important (as in priority) environmental factors that constitute the sanitary epidemiological welfare and the health of the population of the Russian Federation were:

- social and economy factors, with the approximate number of the population subject to them and with the most prominent influence of these factors on health - 
94.4 million people in 53 subjects of the Russian Federation (64.3\% of the population of the Russian Federation);

- sanitary and hygienic (chemical, biological, physical) factors with the approximate number of the population subject to them and with the most prominent influence of these factors on health (91.4 million people in 50 subjects of the Russian Federation (62.3\% of the population of the Russian Federation);

- way of life factors (tobacco smoking, alcohol consumption, food quality) with the approximate number of the population subject to them and with the most prominent influence of these factors on health ( 71.5 million people in 44 subjects of the Russian Federation (48.7\% of the population of the Russian Federation).

According to the Federal law no. 184-FZ [6], risk is the possibility of causing harm to life or health of the population, assets of physical or legal entities, state or municipal assets, environment, life or health of animals and plants, with the degree of this harm taken into consideration. As we can see, the first place is given to life and health.

In the context of the influence of environmental conditions on human health, there are three types of risk:

- mathematical possibility of development of a certain adverse effect (individual risk);

- an expected number of the development of those effects among the population or a part of it (population risk);

- the excess level of established allowed levels of the impact of the harmful factor or expertly established safe levels of the impact based on the generalization of all the available experimental and epidemiological information.

\section{Methods}

Health risks assessment methods, as part of the risk analysis procedure, which includes not only risk assessment, but also risk management and distribution of information about risks, are an effective way of solving legal issues in the 'environment condition human health' area, and it is based on an assumption that risk is the function of two arguments: danger and exposure. That is why four stages of work are distinguished when these methods are being implemented [4]: danger identification, exposure assessment, characteristics of 'exposure-effect' correlation, risk characteristics.

At the same time, at the stage of danger identification, the goal is to establish factors of physical, chemical or biological nature that pose the greatest risk for human health in the current situation. And exposure means information about real or potential dosage certain groups of the population are exposed to (or will be exposed to), which is achieved by using calculations or tools to examine environmental conditions of the population and their behavior within that environment.

From the psychological point of view, special attention should be paid to the fact that consumers of medical ecological information tend to identify danger and risk without taking exposure assessment into consideration within the context of the assessed situation, that leads to errors in management decision-making both on the individual level and on the level of social task-solving, and it unreasonably increases the level of anxiety in the population. It is quite sufficient to mention a very common situation with the quality of 
tap water, when the information about harmful chemical substances present in it leads to using individual means of additional purification or switching to alternative water sources even if the risk level, based on real exposure numbers, does not exceed acceptable parameters. A similar situation often occurs with the quality of food or other factors of the human environment. Let us consider one example.

For example, we need to assess carcinogenic risk for the situation of drinking water pollution with chloroform in $1 \mathrm{mg} / \mathrm{l}$ concentration when it is consumed 3 liters per day over the expectant life span of 72 and an average weight of $70 \mathrm{~kg}$. As a rule, chloroform can appear in the tap water when chlorination is used as microbe disinfection when organic substances are present in the source water.

Chloroform is a dangerous substance and according to [4] it can cause carcinogenic effect that leads to cancerous neoplasms. According to the classification of the International Agency for Research on Cancer (IARC), it is a carcinogen of the 2B group, with the carcinogenic risk potential of $0.0061(\mathrm{mg} /(\mathrm{kgxday}))^{-1}$. Given the set parameters, chloroform exposure (ADD) entering human body over the expected life span will be:

$\mathrm{ADD}=31 \times 1 \mathrm{mg} / 1 / 70 \mathrm{~kg}=0.043 \mathrm{mg} / \mathrm{kg}$

and carcinogenic risk (in this case the possibility of cancer) will be:

Risk $=0.043 \times 0.0061=0.00026$

which is 26 times higher than the acceptable parameter for this given situation.

At the same time, if we change the specifications and try, for example, to assess the risk when the water is consumed not throughout the expected life span, but only for one year (for example, this can be the transition period to the alternative system of water preparation in the system of centralized water service without the use of chlorination), then the exposure and hence the health risk will be 72 times less, which will give the cancer possibility of 0.00004 , which is an acceptable parameter. In this given example we do not advocate rejecting the means of individual purification or an alternative water system, especially if the pollution exceeds hygienic norms - this is the matter of water producer and consumer, as well as supervision and control authorities. Here we only speak about the rational understanding of the current situation in relation to human health.

Thus, the important thing here is the development of methods of psychological support for providing the consumers with medical ecological information, directed not only at achieving the correct understanding of health risk levels formed by the environment, but also lowering the anxiety caused by the information about the dangers thanks to the correct understanding of the appearing risks and about the ways of controlling them with available means.

Human anxiety is an individual psychological characteristic which is expressed in constant readiness of a person to feel great degree of alarm because of minor reasons. Elevated level of anxiety is often caused by personality features, because of weak nervous processes, but there is a number of factors that lead to anxious state, which include: genetic inclination, hypodynamia, negative thinking, personal experiment, somatic illnesses and environment.

A certain level of anxiety is natural and mandatory and is not seen as a negative characteristic, because there is a personal level of 'useful anxiety' for each person. This characteristic, anxiety, greatly influences behavioral reactions of a person and the ability to assess their own condition in this area is an important component of self-discipline and self-control. 
There are different types of anxiety: personal and situational anxiety, mobilizing and relaxing anxiety.

The first type of anxiety is a personal characteristic that is found in the stable predisposition to anxiety and nervousness not related to the gravity of life circumstances. This type of anxiety is characterized by the feeling of inexplicable fear and threat to personal life. A person with this trait is prone to seeing all events as dangerous.

While studying the anxiety phenomenon, Ch. D. Spielberger explained personal anxiety as a motive or an acquired life position that pushes a person to understand a large number of regular situations as alarming, dangerous, and leads to reacting to this danger with anxiety. Intensity of these reactions does not correlate with the real danger.

Ch. D. Spielberger describes situational anxiety as conscious feeling of danger, individual to every person, accompanied by or connected to activation or excitement of autonomous nervous system. He believed that the special nature of the situation a person is in and the level of their personal anxiety influence the level of situational anxiety and in its turn it influences the person's behavior. Situational anxiety is caused by a certain situation or an event that causes alarm. This state can be found in every person facing serious life problems and possible trouble, which is considered to be normal, because it facilitates mobilization of personal resources. The state of situational anxiety can be caused by natural catastrophes, civil unrest, negative news in mass media.

Mobilizing anxiety gives an additional stimulus to act and relaxing anxiety paralyzes a person during crucial moments of life. Researchers also proved that anxiety changes in time as a function of stress degree of a person and varies in intensity.

Karen Horney states that intensity of anxiety is equivalent to the meaning the dangerous situation has for a person. A person is not conscious about the reasons of their anxiety. The task of the psychologist in this approach will be defining the meaning a certain situation has for a person.

Hence, if the level of anxiety of consumers of medical ecological information does not correspond to the level of danger, there is the need of developing a program of psychological support of providing information, which include methods of psychological diagnostics of the type and level of anxiety and psychological correction of psychoemotional state of a person.

\section{Results}

Taking psychological problems into the consideration, their spread, power of influence on the quality of life of the population, dominant psychoemotional state (anxiety, depression), we can suggest the following psychological program of support, consisting of three stages: diagnostic, psychological correction and psychological social support.

\section{Diagnostic stage}

Diagnostic stage should include a social questionnaire (age, living conditions and work) and psychological diagnostics, including methods that allow for quality and quantity assessment of psychoemotional background.

Anxiety test (developed by Ch. D. Spielberg, adapted by Y.L. Khanin) allows for assessing the level of reactive and personal anxiety at the current moment. 
This method consists of forty statements: 20 statements to establish the level of reactive anxiety and 20 statements to establish the level of personal anxiety; all parameters of this method are calculated with the help of a special key $[7 ; 8]$.

Self-evaluation examination. A test by T.V.Dembo - S. J. Rubinstein. The method was suggested by S.J.Rubinstein (1970). It uses the technique by T.V.Dembo, which helped to reveal the ideas of the examinee about their own happiness. S. J. Rubinstein widened the method and introduced four scales instead of one (health, mental development, personality and happiness).

According to the method of T. V. Dembo - S. J. Rubinstein the examinee is asked to define their own state according to the scales of self-evaluation that consider a number of nuances reflecting the level of expression of certain personal features.

The test is designed for psychological diagnostics of self-evaluation according to the following parameters: height, stability, realistic level, critical level of the self-evaluation, self-discipline, self-satisfaction, inconsistency of self-evaluation parameters, mature attitude to values, presence and the nature of compensatory mechanisms that take part in the formation of 'Self-concept', the nature of problems and their compensations.

M. Luscher color test helps to define psychophysiological state of a person, their stressresistance, activity and communicational abilities. In addition, the projective color test helps to establish relevant psychological state of a person with the help of their practical variables that have quality expression: psychological fatigue, psychological tension, anxiety, emotional stress, workability, summary deviation from the autogenic norm.

The results of psychological diagnostics and social data make it possible to conduct a complex assessment of the most important personality issues and to offer a client to take part in the program of psychological correction, which consists of individual and group sessions.

\section{Psychological correction}

Psychocorrection groups last for 10 sessions 2 hours each. Goals of each session can be 'simple' - reacting to negative emotions and experiences, or 'complex' - reevaluation of attitude to oneself.

A mandatory condition of group work is forming groups according to age characteristics, because tasks and group dynamics in art-therapy are different in different age periods.

Group form of work makes it possible to cover a wide number of clients of different age, psychopathological changes, thus creating conditions for communication, support and self-expression with the use of art-therapy methods.

"As an independent discipline, art-therapy originated from psychoanalysis, like almost all types of psychotherapy. Art as a therapeutic method was first used by Margaret Naumburg (1966), who was raised in the spirit of traditional psychoanalysis, where the main focus is on free associations and interpretation" [9].

Art-therapy shows positive results in interpersonal interactions as well: "therapy does an important job of deconstructing negative forms of interpersonal communications and helps to achieve positive social and therapeutic results" [10].

The task of an art-therapist is to create a safe art-therapeutic environment, where the main means of interaction is a constructive dialogue, based on creating and examining 
an art product of a client, "client-art product-psychologist", where the client will feel protected to express their feelings.

Art-therapy can be used for any emotional disorders, as well as for psychosomatic conditions. It is not recommended only for grave psychopathic or psychiatric disorders that make it impossible for the clients to process and verbalize their own feelings.

Art-therapy process usually consists of three stages.

- Stage one - entering art-therapeutic environment and the beginning of art activity of the client.

- Stage two - productive art activity of the client.

- Stage three - the conclusion.

At the first stage, the psychologist gives explanations about the process of work, rules and learns more about the client. At the end of it, they establish the work goal, agree on the plan of work, duration and possible alterations of it.

At the second stage of the art-therapeutic process, the client transitions from getting acquainted with the art-therapeutic environment and chaotic behavior to productive art activity, creating 'symbolic images' and understanding their interpersonal meaning, clients develop a certain attitude to certain types of art activity. Clients learn to creatively complete tasks given by the psychologist, overcoming their negative state - skepticism, tension.

The third stage summarizes the whole art-therapy process and makes it possible to assess the effectiveness of psychologist's work. It is important to agree on the finish date of the sessions in advance, because the therapy process must come to a logical conclusion and not cause strong negative feelings in the client. At the end of the session, clients are offered to take their art works with them or leave them to be used for scientific purposes [11].

\section{Psychological social support stage}

After the end of the psychological correction program, clients may continue working with the psychologist as part of psychological social support -1 consultation a month.

\section{A construct of the program of psychological support of medical ecological information consumers}

Program goal: improving psychoemotional characteristics of clients.

Tasks:

1. Reveal main psychoemotional disorders by using in- and outer-program complex of psychodiagnostics, conversation and active observation.

2. Help the clients to react to negative emotion.

3. Create conditions for mutual support of the group members.

4. Decrease anxiety level.

5. Teach art-therapeutic methods of effective tension release, improvement of one's own state and activation.

Calculating work hours

Stage 1. The program includes mandatory psychodiagnostics at the first session, which takes from 40 to 60 minutes, depending on the age and methods used. Methods are carried out using printed forms. 
The next session is appointed.

According to the diagnostics results, the psychologists makes a decision whether the client can take part in group art-therapy. It is not recommended to work in groups if the client shows:

- overly negative attitude towards other people (negativity towards working in a group up to refusal)

- excessive aggression (which can indicate an upcoming crisis with complications and demands immediate additional individual session to reveal reasons for high aggression and irritation).

Stage 2. If none of the above is present, the psychologist informs the client about the results of the diagnostics (to the necessary degree) and suggests attending 10 sessions in an art-therapy group (12-15 members). The psychologist informs about the goals, the group, the time and place and gives an invitation (program summary). The duration of the second session is $30-40$ minutes.

Stage 3. The duration of art-therapy group sessions is 2 academic hours (90 minutes), including 10 minutes warm-up, 30 minutes art work, 45 minutes discussion, 5 minutes conclusion (Table 1). Sessions occur twice a week.

Table 1. Calculating work hours

\begin{tabular}{|c|c|c|}
\hline Program stage & Time spent (maximum) & Additional time (technical) \\
\hline 1 & 1 hour (60 minutes) & 15 \\
\hline 2 & $30-40$ minutes & 2.5 hours (150 minutes) \\
\hline 3 & 20 academic hours (900 minutes) & \\
\hline
\end{tabular}

Technical time -15 minutes before and after session were spent on getting the room ready for the clients.

Equipment necessary for quality work with the clients:

1. A room for individual sessions and psychodiagnostics (no less than 15 square meters, with double doors or a hallway, a bright window, artificial light, walls of pleasant light colors, a table for the diagnostics, chairs - no less than 2, a coat hanger and a stand for personal belongings of clients, a cabinet to store diagnostic material).

2. A room for group art-therapy (no less than 50 square meters, specifically equipped for 'clean' and 'artistic' work, 2 walls should have special places to hang group art works. The room should be in neutral colors, it should have lights, a sink and a place for rest, no less that 15 coat hangers (in the hallway or a special zone for outwear), chairs, shelves, stands and so on for bags and other personal belongings)

3. Inventory - paper, paints, pencils, name tags with colorful threads, folders to store art works, dry pastels, oil pastels, wax crayons, coal, sanguine, felt pens, music player with 'surround sound' option, a ball, a riddle box, emotion cards.

4. Meditation equipment - chairs with semi-soft seats and tall straight backs. The floor should be covered with thick linoleum that can keep the cold away (meditation can be carried out barefoot if the participants wear high heels) and makes it easy to keep the room clean and remove spilled water and paints. 
Table 2 represents an approximate complex of psychocorrectional sessions.

Table 2. Approximate complex of psychocorrectional sessions

\begin{tabular}{|c|c|c|}
\hline Stage & Session goal & Session contents \\
\hline Session 1 & Getting to know each other & $\begin{array}{l}\text { Exercises 'Introduction' } \\
\text { 'My presentation' 'Free chair', 'Person on a } \\
\text { chair' } \\
\text { Home task }\end{array}$ \\
\hline Session 2 & $\begin{array}{l}\text { Establishing a closer emotional contact } \\
\text { between the group members }\end{array}$ & $\begin{array}{l}\text { Warm-up exercises } \\
\text { 'Thunder and lightning' 'Brownian motion' } \\
\text { Visual arts therapy 'Three drawings' } \\
\text { Session-end ritual }\end{array}$ \\
\hline Session 3 & $\begin{array}{l}\text { Widening the knowledge of group } \\
\text { members about themselves, analysis of } \\
\text { life values }\end{array}$ & $\begin{array}{l}\text { Warm-up exercises } \\
\text { Visual arts therapy: 'My emblem' } \\
\text { Session-end ritual }\end{array}$ \\
\hline Session 4 & $\begin{array}{l}\text { Becoming aware of their own true state, } \\
\text { revealing personal resources with the } \\
\text { help of art }\end{array}$ & $\begin{array}{l}\text { Warm-up exercises } \\
\text { 'Body parts dance' } \\
\text { Visual arts therapy: 'Magical land' } \\
\text { Session-end ritual }\end{array}$ \\
\hline Session 5 & $\begin{array}{l}\text { Developing the feeling of unity within the } \\
\text { group, introducing music therapy }\end{array}$ & $\begin{array}{l}\text { Psychogymnastics exercise: 'Repeat the } \\
\text { pose' } \\
\text { Music therapy: 'Orchestra' } \\
\text { Session-end ritual }\end{array}$ \\
\hline Session 6 & $\begin{array}{l}\text { Developing the ability to be aware of } \\
\text { and express their own true feelings and } \\
\text { emotions, to relieve fear and psychological } \\
\text { barriers, to get rid of hidden suppressed } \\
\text { emotions }\end{array}$ & $\begin{array}{l}\text { Warm-up exercises } \\
\text { 'Associations' 'Dialogue' } \\
\text { Visual arts therapy 'Analog lines' } \\
\quad \text { Session-end ritual }\end{array}$ \\
\hline Session 7 & $\begin{array}{l}\text { Stimulating the process of 'remembering' } \\
\text { bright, best moments in the lives of group } \\
\text { members }\end{array}$ & $\begin{array}{l}\text { Dance movement therapy. Circle dance } \\
\text { Visual arts therapy 'The happiest moment of } \\
\text { my life' } \\
\text { Session-end ritual }\end{array}$ \\
\hline Session 8 & $\begin{array}{l}\text { Reinforcing life resources of group } \\
\text { members }\end{array}$ & $\begin{array}{l}\text { Warm-up exercises } \\
\text { Visual arts therapy: 'Rainbow', 'Self-portrait' } \\
\text { Session-end ritual }\end{array}$ \\
\hline Session 9 & $\begin{array}{l}\text { Shaping constructive view on the client's } \\
\text { future }\end{array}$ & $\begin{array}{l}\text { Warm-up exercises: } \\
\text { 'Magic pill', 'Rose and thistle' } \\
\text { Visual arts therapy 'What I'd like to be' } \\
\text { Session-end ritual }\end{array}$ \\
\hline Session 10 & $\begin{array}{l}\text { Understanding and consolidating the } \\
\text { experience received in the process of } \\
\text { group work. Building a creative life } \\
\text { program }\end{array}$ & $\begin{array}{l}\text { Psychogymnastics exercise: 'Invitation', } \\
\text { group members in pairs non-verbally } \\
\text { suggest each other plans for tomorrow }\end{array}$ \\
\hline
\end{tabular}




\section{Example of the first and the last sessions}

\section{Session 1}

Goal: Group members getting to know each other. Relieving tension in group members.

Exercises for session 1:

- Exercise 'Introduction'

- Each member says their name and an adjective that characterizes them and starts with the first letter of their name

- Visual arts therapy: 'My presentation'

By using different art materials, group members write their name on a card and draw their symbol, then they explain their symbol and name the goal for the sessions and their expectations.

- Psychogymnastics exercise 'Free chair'

- Feedback - discussing feelings that have appeared during the exercises

- Psychogymnastics exercise 'A person on a chair'

Each member needs to do a short, 1-2 minutes long, self-presentation, they need to tell it in third person.

- Feedback - discussing feelings that have appeared during the exercises

- Home task: in the next three days pay special attention to the outside world nature, relations between people - and try to remember or write down these observations.

- Session-end ritual 'Applaud'

\section{Session 10}

Goals:

- Understanding and consolidating the experience received in the process of group work.

- Building a creative life program

Exercises for session 10:

- Psychogymnastics exercise 'Invitation', group members in pairs non-verbally offer each other plans for tomorrow

- Color/decorate an item brought from home for the tea party.

Exercise 'Main values'. The psychologist gives out blanks with an image of an island, like an outline map, divided into 10 parts. Group members select 10 main life values for themselves and color each area that match each of the values, then make a pretty frame. It is recommended to hang this drawing on the wall at home.

- Feedback - discussing feelings that have appeared during the exercises

- Session-end ritual 'Applaud'

- Tea party using decorated tableware.

According to the results of the scientific research conducted as part of graduate qualification papers of SPbSIPSW students over the course of 25 years it was soundly proved that there were positive results after the use of art-therapy methods in psycocorrectional work with clients of different age groups with psychoemotional disorders. 


\section{Discussion, conclusions}

Thus, each citizen of the Russian Federation by evoking their constitutional right to receive valid information about their environmental conditions should also be able to use it correctly, not to harm their own health, welfare of other people and the country in general by their action or inaction. Since medical ecological information is formed as part of control and supervision activity of governmental authorities, such as Rospotrebnadzor, Rosprirodnadzor, Hydrometeo service and other authorities, there arises a problem of its rational interpretation by individual citizens and groups of the population, most of whom do not have professional skills needed for this and it often leads to incorrect understanding of the information, anxiety or disregard of risks. Methods of health risk assessment $[4 ; 10]$ suggest a separate block of procedures, called 'informing about risks', which we believe should be carried out by specialists who possess necessary knowledge in both preventive medicine and ecology, as well as social psychology, who can give information to the interested groups not only about medical ecological risks, but also lower anxiety through teaching citizens of RF how to understand it correctly and use corresponding psychological methods and techniques. Specialists like this should be a part of social psychological support centers for the population and have training from field-specific educational facilities.

\section{References}

1. Kovyneva O.A., Gerasimov B.I. Quality of life management. Tambov, Tambov state technical university Publ., 2006. 89 p. (In Russian)

2. Okrepilova I. G., Venediktova S. K. Quality of life management. St. Petersburg, SPBSUEF Publ., 2010. 104 p. (In Russian)

3. Decree of the Chief Sanitary Physician of the Russian Federation and the Chief State Conservation Inspector of the Russian Federation "On using risk assessment methods to control the quality of environment and health of the population in the Russian Federation" as of 10.11.97 no. 25 and 03-19\24-3486. (In Russian)

4. Manual on health risk assessment of the population under the exposure of chemical substances that pollute environment. Moscow, Federal center of state epidemic control of the Ministry of Health of Russia, 2004. 143 p. (Manual P2.1.10.1920-04). (In Russian)

5. On the condition of sanitary epidemiological welfare of the population in the Russian Federation in 2018: government report. Moscow, Federal supervision service in the sphere of consumer right protection and human welfare, 2019. 254 p. (In Russian)

6. Federal law as of 27.12.2002 no. 184-FZ "On technical regulation”. (In Russian)

7. Karelin A. A. Large encyclopedia of psychological texts. Moscow, EKSMO Publ., 2009. 146 p. (In Russian)

8. Kupriyanov R. V. Psychodiagnostics of stress: practical guide, comp. by Kupriyanov R. V., Kuzmina J. M. Ministry of education and science of RF, KNITU, 2012.212 p. (In Russian)

9. Kiseleva M.V. Art-therapy in practical psychology and social work: study guide. St. Petersburg, Rech Publ., 2009. 336 p. (In Russian)

10. Bezzubik K. V., Naumova S. M., Efanov E. V., Obraztsov S. N. Contemporary creative art-therapeutic approach as the means of achieving and maintaining physical and psychological welfare. Service in Russian and abroad, 2009, vol. 3, pp. 49-56. (In Russian)

11. Kiseleva M. V., Kulganov V. A. Art-therapy in psychological counseling: study guide. St. Petersburg, Rech Publ., 2016. 64 p. (In Russian)

Authors' information:

Marina V.Kiseleva - PhD (Medicine); marina.v.kiseleva@gmail.com

Anatoly V.Kiselev - MD; anatolii.kiselev@szgmu.ru 